Supporting Information

\title{
A Composite Lithium Protective Layer Formed in Situ for
}

\section{Stable Lithium Metal Batteries}

\author{
Yingzhen Zhang ${ }^{1,2}$, Chunwen Sun ${ }^{1,2,3 *}$
}

${ }^{1}$ CAS Center for Excellence in Nanoscience, Beijing Institute of Nanoenergy and Nanosystems, Chinese Academy of Sciences, Beijing 100083, P. R. China.

${ }^{2}$ School of Nanoscience and Technology, University of Chinese Academy of Sciences, Beijing, 100049, China.

${ }^{3}$ School of Chemical and Environmental Engineering, China University of Mining \& Technology (Beijing), Beijing 100083, China

E-mail: sunchunwen@binn.cas.cn; springwensun@163.com 


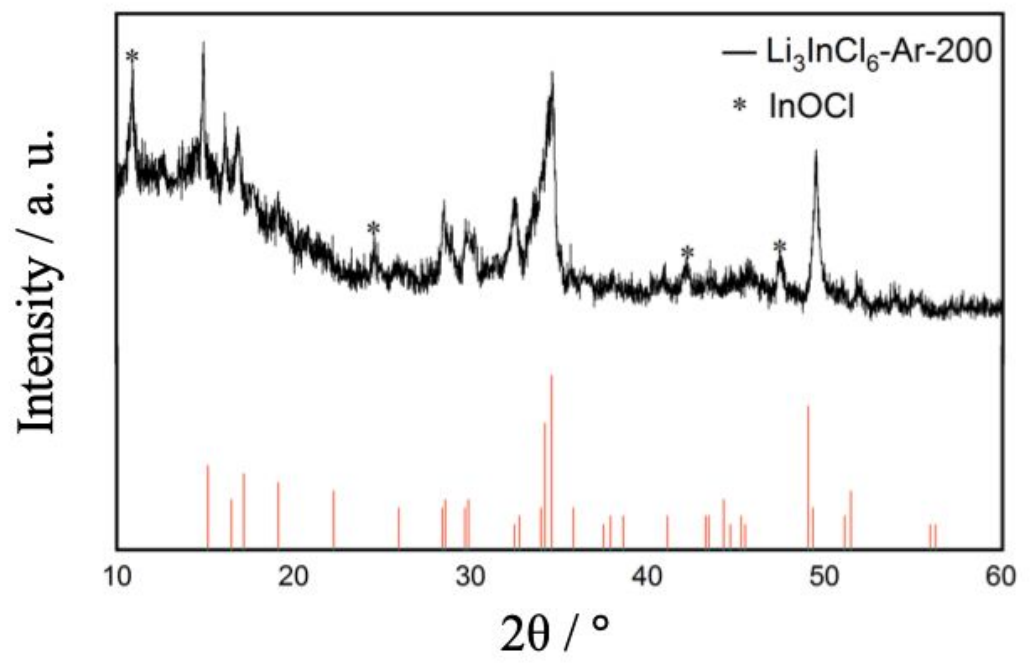

Figure S1. XRD pattern of the $\mathrm{Li}_{3} \mathrm{InCl}_{6}$ powder after removing water.
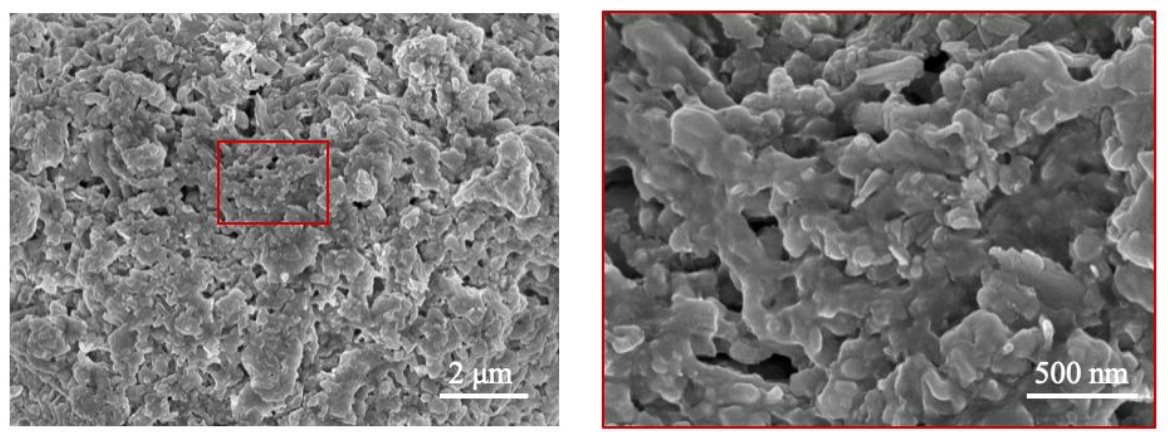

Figure S2. SEM images of the as-prepared $\mathrm{Li}_{3} \mathrm{InCl}_{6}$ particles at different magnifications. 


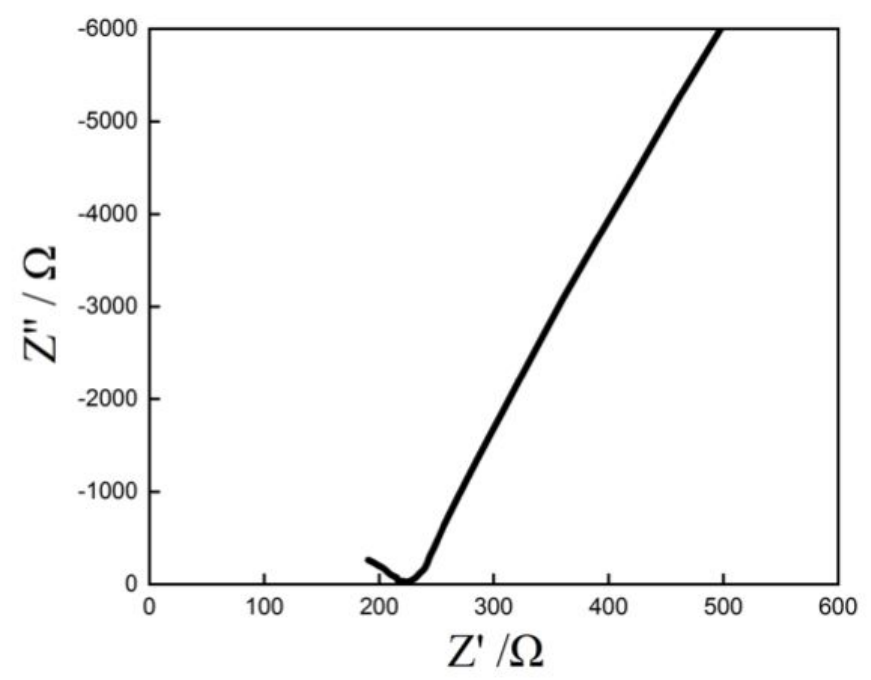

Figure S3. Electrochemical impedance spectrum (EIS) of $\mathrm{Li}_{3} \mathrm{InCl}_{6}$ pellet tested at $25{ }^{\circ} \mathrm{C}$.

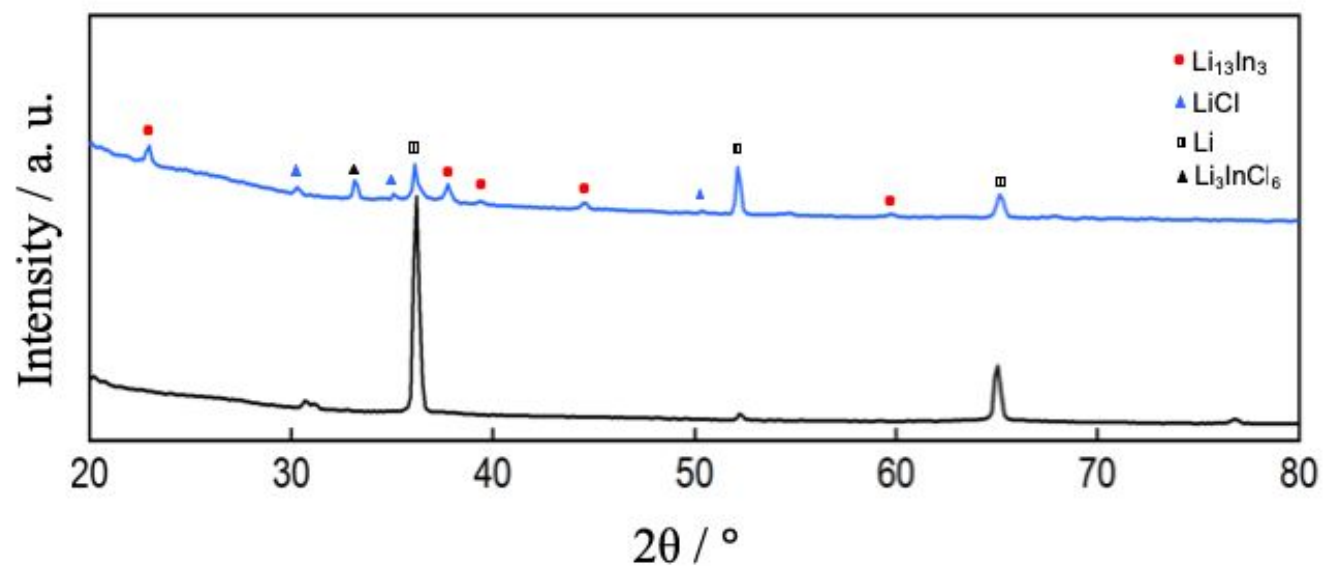

Figure S4. XRD patterns of the Li electrode surface in symmetric cells with the blank DOL/DME-based electrolyte (black) and $50 \mathrm{mM} \mathrm{Li}_{3} \mathrm{InCl}_{6}$ added electrolyte (blue) after testing for 7 cycles at a current density of $1 \mathrm{~mA} \mathrm{~cm}^{-2}$. The standard patterns of $\mathrm{Li}_{13} \mathrm{In}_{3}$ (JCPDS file No. 15-0401), Li (JCPDS file No. 33-0615) for, for $\mathrm{Li}_{3} \mathrm{InCl}_{6}$ (JCPDS file No. 44-0287) and LiCl (JCPDS file No. 04-0664) are referred. 

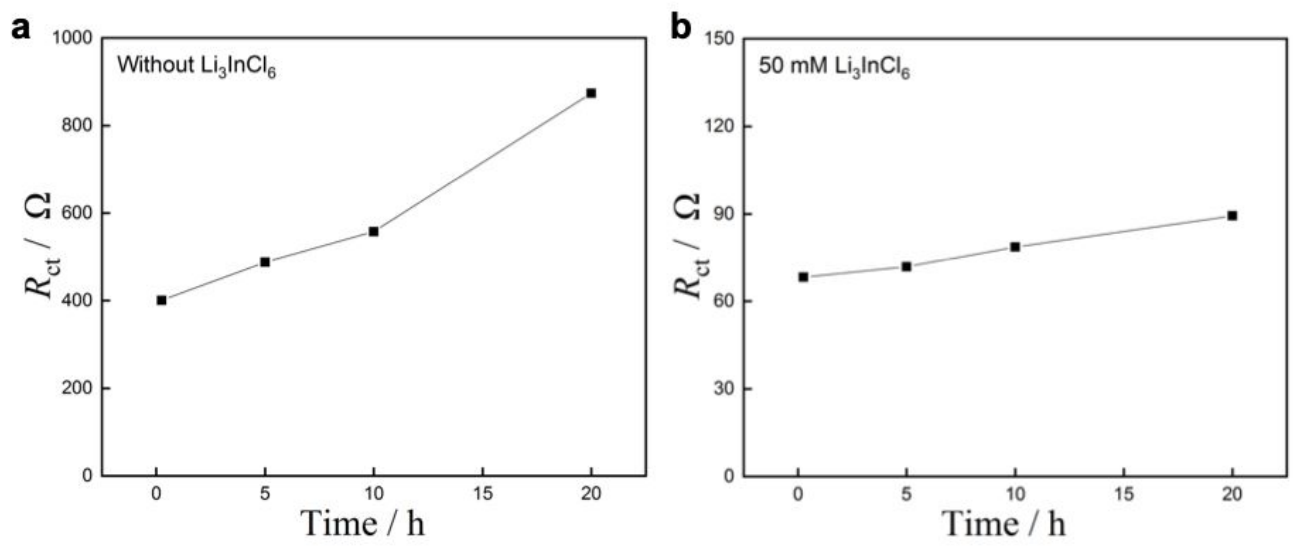

Figure S5. Charge transfer resistance of the symmetric Li|Li cells with (a) The blank DOL/DME-based electrolyte and (b) $50 \mathrm{mM} \mathrm{Li}_{3} \mathrm{InCl}_{6}$ added electrolyte after resting for 20 hours at open-circuit condition.

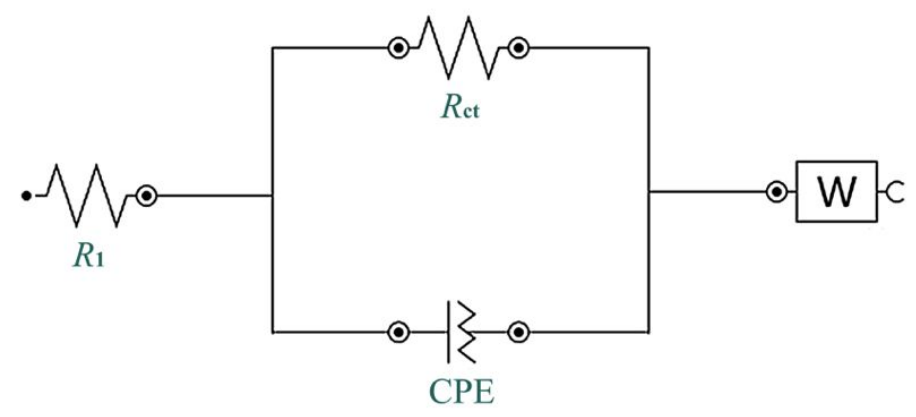

Figure S6. The equivalent circuit used for fitting the electrochemical impedance spectra. 


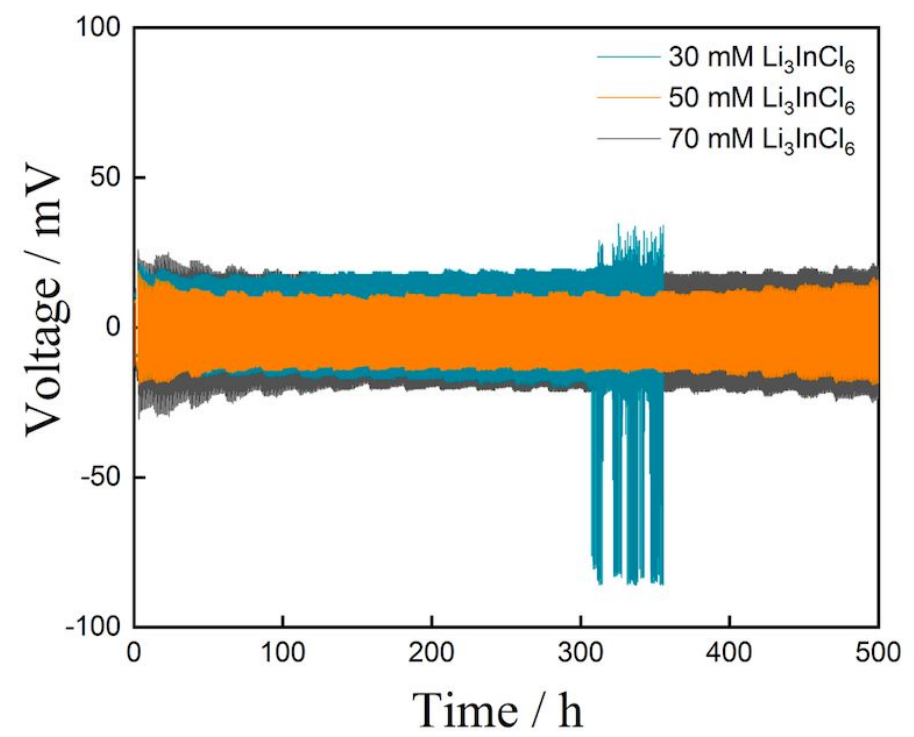

Figure S7. Voltage profile of lithium plating/stripping on the symmetric cells using $\mathrm{Li}_{3} \mathrm{InCl}_{6}$-added electrolytes with varied concentrations at a current density of 1 $\mathrm{mA} / \mathrm{cm}^{2}$ and capacity of $0.5 \mathrm{~mA} \mathrm{~h} \mathrm{~cm}^{2}$.

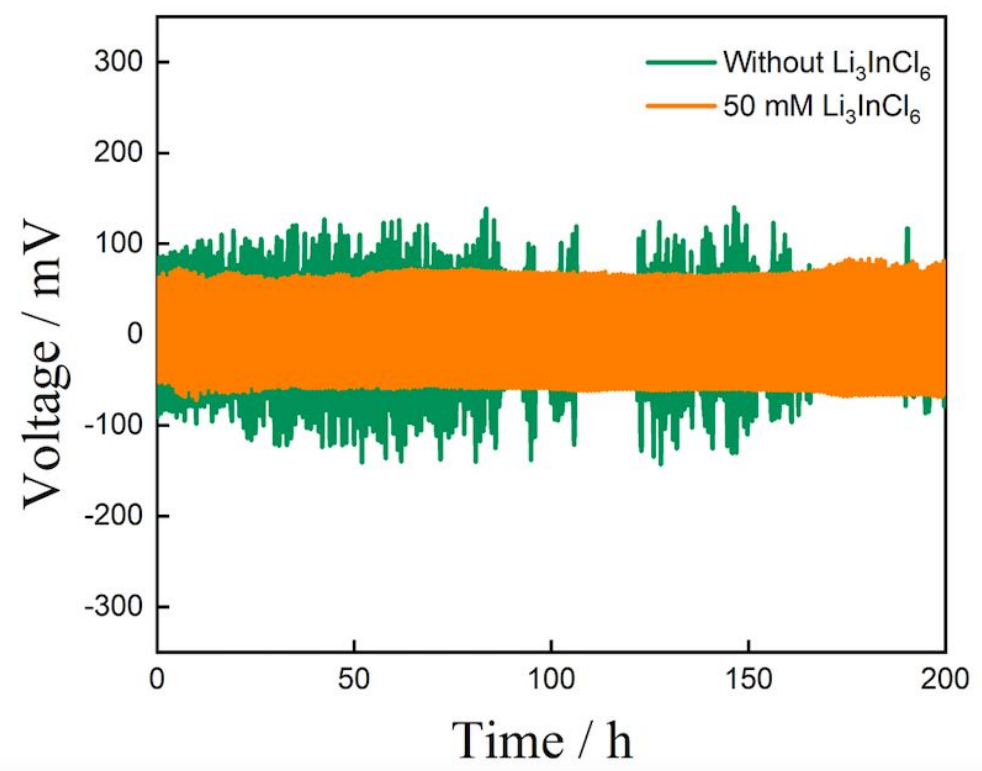

Figure S8. Voltage profile of lithium plating/stripping on the symmetric cells with blank and $50 \mathrm{mM} \mathrm{Li}_{3} \mathrm{InCl}_{6}$ added DOL/DME-based electrolyte (current : $4 \mathrm{~mA} \mathrm{~cm}{ }^{-2}$; capacity $: 2 \mathrm{~mA} \mathrm{~h} \mathrm{~cm} \mathrm{~cm}^{-2}$. 


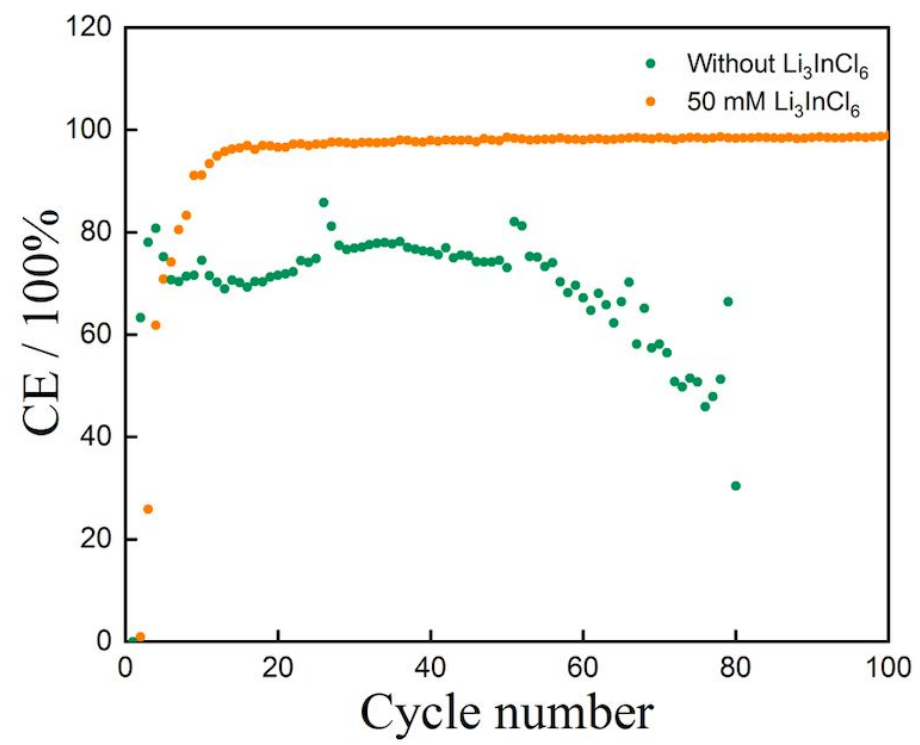

Figure S9. Comparison of $\mathrm{CE}$ of $\mathrm{Li} \mid \mathrm{Cu}$ coin cells with blank and $50 \mathrm{mM} \mathrm{Li}_{3} \mathrm{InCl}_{6}$ added DOL/DME-based electrolyte at a current density of $1 \mathrm{~mA} \mathrm{~cm}$. 

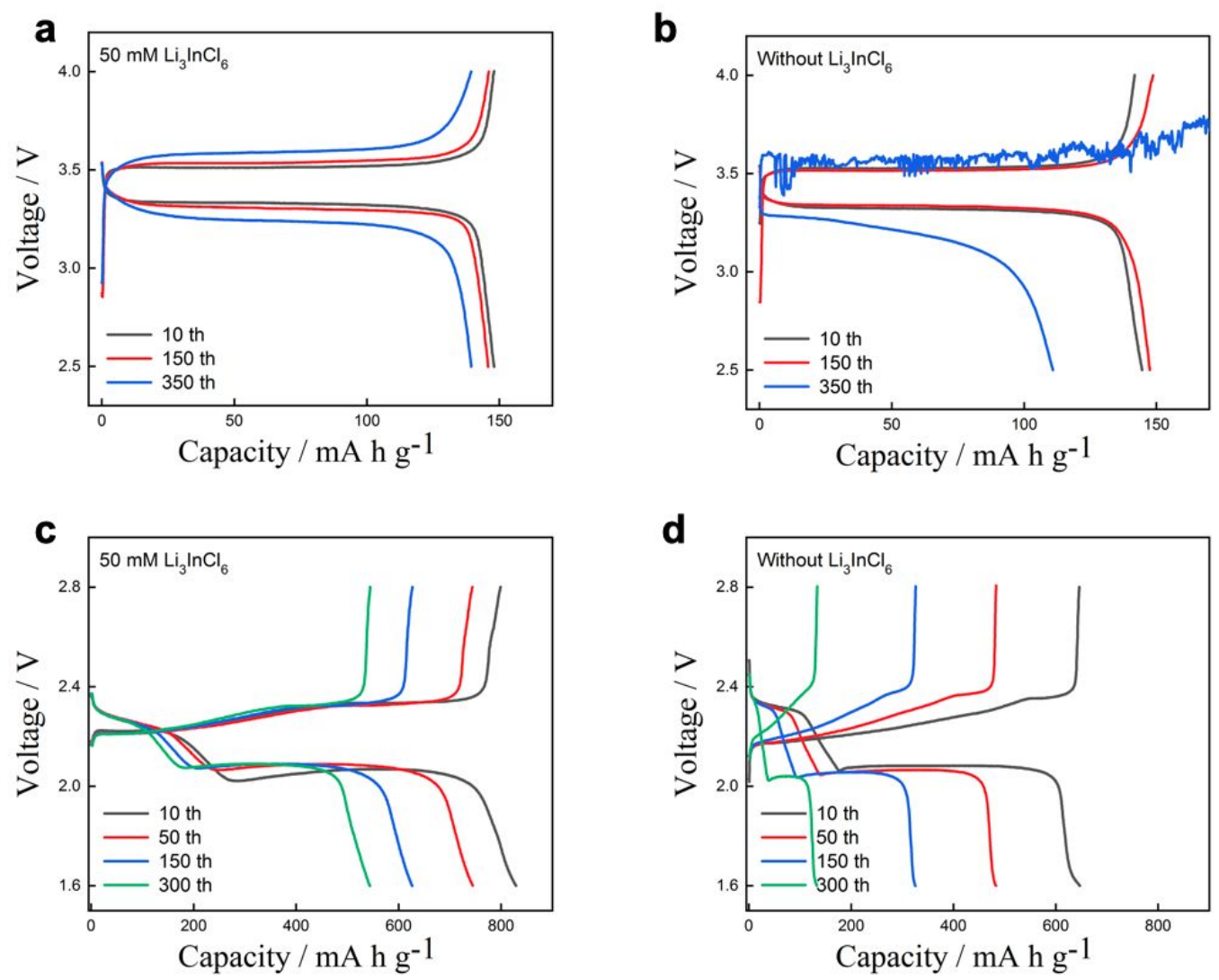

Figure S10. The charge/discharge curves of $\operatorname{Li} \mid \operatorname{LFP}(a, b)$ and $\operatorname{Li} \mid \mathrm{S}(\mathrm{c}, \mathrm{d})$ batteries for different cycles with blank and $50 \mathrm{mM} \mathrm{Li}_{3} \mathrm{InCl}_{6}$ added DOL/DME-based electrolytes. 